\title{
ERRATUM \\ Erratum to: Habitat Use and Activity Patterns as an Indication of Fragment Quality in a Strepsirrhine Primate
}

\author{
Denise N. Gabriel
}

Published online: 31 May 2013

(C) Springer Science+Business Media New York 2013

\section{Erratum to: Int J Primatol (2013) 34:388-406 \\ DOI 10.1007/s10764-013-9668-x}

The original version of this article unfortunately contained a mistake in Acknowledgments section. The change is underlined as follows:

Acknowledgments I thank the Natural Sciences and Engineering Research Council of Canada (NSERC) and Primate Conservation Inc. for providing the funding for this research. Thanks also go to J. Ratsimbazafy and the team at Groupe d'Etude et de Recherche (GERP), the University of Antananarivo, and the Ministere de l'Eau et des Forets for research permission and facilitation; to R. Simmons and I. SchneiderCrease for their field assistance; to P. Andrianomena for his skilled guidance in the forest; to J. Hale for his advice and assistance in translating GPS data; and to the three anonymous reviewers who took the time to edit this manuscript. This research complies with the current laws established by the Ministere de l'Eau et des Forets and the government of Madagascar. Special thanks to my supervisor, Dr. Lisa Gould, for introducing me to the research sites and for providing valuable feedback and advice throughout the preparation of this manuscript.

The online version of the original article can be found at http://dx.doi.org/10.1007/s10764-013-9668-x.

D. N. Gabriel $(\bowtie)$

Department of Biology, University of Victoria, STN CSC, Victoria, BC V8W 3P5, Canada

e-mail: denisegabrie@gmail.com

D. N. Gabriel

Department of Anthropology, University of Victoria, STN CSC, Victoria, BC V8W 3P5, Canada 